\title{
From Countercultures to Suburban Cultures: Frank Zappa after 1968
}

\author{
Benjamin Halligan
}

Keywords:

Frank Zappa

Suburbia

1968

Counterculture

Sexual liberation

"Freaks"

Valley girl

Ronald Reagan

Suburbia would prove to be the terminus of Frank Zappa's satirical project. In the final analysis, the ringmaster of freaks, a mother to the North American counterculture, and champion of outsiders, would find himself outnumbered and outmanoeuvred by the rising tide of 'plastic people'. The nature and efficacy of Zappa's last formal political stand at this juncture is the concern of this chapter. It is the precise social and political moment of this juncture - as the 1970s turned into the 1980s, and the dawn of the Reagan era, perceived as the final routing of "the long 1960 s" - that lends a context to Zappa's seemingly reactionary sentiments, a framing which goes some way to recover Zappa's work from its detractors.

Those detractors typically admit to bafflement and frustration at Zappa's infantile and puerile preoccupations of these years. Despite the ingenuity and forensic textual analysis of those who would seek to defend Zappa against the serious charges 
arising from his recordings at this time (homophobia, racism, violent misogyny, red baiting), principally associated - in print, at least - with Watson and Leslie (2005), Zappa's cultural significance seems to have waned rapidly since his death. In his study of the music of 1989, for example, Clover quickly passes over Zappa: although his legacy is noted as central to Clover's concerns of the intermeshing of music, social upheaval and formal political change ('... despite his role as unofficial attaché to Václav Havel's government, and despite the memorial statue of Zappa to be found in Vilnius, Lithuania...', (Clover 2009: 6-7)), Zappa's presence in the music scene of 1989 is considered marginal from Clover's twenty year perspective. At best, Zappa is indicative of earlier paradigms of music and change; at worse (and in a moment of the widespread infiltration and subversion of the mainstream: the second summer of love and early manifestations of grunge), irrelevant.

Indeed, at this rough point in Zappa's own career, after a run of albums that increasingly privileged instrumental music over satirical social content (a transition apparent in the Synclavier use of Frank Zappa Meets the Mothers of Prevention from 1985 and with the full shift to 'serious' and Zappa-executed compositions marked by Jazz from Hell of 1986), and with the data-dump-like release of a dozen or so official live double albums between 1988 and 1992, Zappa would seem to have abandoned any claim to contemporary and popular relevancy. The instrumental and compositional, of confounding complexity, with increasingly difficult challenges to live performance and appreciation, would preoccupy his remaining years, culminating in the collaboration with the Ensemble Modern and the density and freeform abstraction of what is typically held to be Zappa's farewell symphony: the composition 'N-Lite' on the posthumous Civilization Phaze III (1995). After 1989, when Zappa had mostly abandoned touring and even guitar playing, satirical music 
was an exclusively archival concern, and best framed via hours of live recordings. Frank Zappa, as he had been known, was ever-more historicised in this tendency: to paraphrase one live release, the question seems to have been posed, and answered in the affirmative: did humour belong in music?

And yet Zappa, as a contemporary composer, remained a diffident figure: wilfully obtuse, avant-garde to the point of delivering "impossible" scores, difficult to take seriously by the Conservatoire (responses that Zappa certainly cultivated and actively courted), ${ }^{1}$ and tedious and humourless for those who knew the Zappa of old. What change had speeded this process, so that the figure of Zappa as a countercultural gadfly, ferocious guitarist, scourge of Republicans, and fearless band leader, had faded into the background by the late 1980s?

It is difficult to avoid the conclusion that it was in Zappa's engagement with the idea of suburbia that his satire began to flounder and his political positions grew increasingly disorientated, and that this ultimately prompted Zappa's retreat from contemporary concerns in favour of a renewal of his lifelong objective to be taken seriously as a composer. However, an engagement with the idea of suburbia had been present throughout Zappa's career, and so connected the countercultural years to those of the onset of Reaganism. A number of Zappa's "lesser" and often more problematic recordings evidence this connection, and so track a key aspect in the evolution of Reaganism and neoliberalism: the routing or dissipation of any latent countercultural sensibilities.

\section{8 and the Suburbs}

\footnotetext{
${ }^{1}$ See particularly the transcript of Zappa's 1984 keynote address to the American Society of University Composers, "Bingo! There Goes Your Tenure", reproduced in (Zappa, Occhiogrosso 1989: 189-194).
} 
Initially the homogenising mores, ambience and routines of suburbia was a target for the counterculture: that horizon of modest expectation for compliant, complacent and uncomplaining members of the workforce. The quiet boredom and desperation beyond the manicured lawns, the essential hypocrisy of the moralism of these mostly white, ex-urban middle classes, their seeming indifference to those outside or back home, those lacking financial security, and a fear of those who would erode financial and civil security, represented the order to be usurped. Timothy Leary's cry of 'tune in, turn on, drop out' was the invite to break free from this gravitation pull, and gain a subjectivity that would have been understood to be both the antithesis, and the breaking, of the suburban fate that awaited. Zappa's entourage and acolytes, and his cosmology of, for Miles (2004: 282), that 'pantheon of anthropological discoveries' - freaks, mothers, hippies, groupies, including The GTOs, and outsiders such as Wild Man Fisher and Captain Beefheart - represented a society of difference and nonconformity: the alternative.

The success and duration of such a collective sensibility - this alternative: the counterculture - is identified by social historians of 'the long 1960s'. Within a decade of 1968, however, revolutionary impulses and radical subjectivities had been nearfully buffered by and absorbed into a new suburbia. Suburbia, once a target, was now a destination. And yet this counter-revolution was one that had also been achieved via an accommodation of the alternative: demands would be mostly met and freedoms readily granted. Boardrooms were thrown open and wealth moderately redistributed as the baby boomer generation - with force, through persuasion, via reassurance, and in the name of progress, after occupations, draft card burning, the full countering of the prevailing culture and, more problematically, and a la Zappa, the trashing of its 
received values and its proposed futures - took the reigns of power, and the keys to the institutions, from their parents.

Left critics of 1968 and, more specifically, left critics of the project of the 'soixante'huitards', tend to accept the success of the social, cultural and institutional upheavals but on specific grounds: demands were met but these demands were intrinsic to post-1945 society, to finesse the burgeoning service and tertiary sectors, as manufacturing resumed its decline, and to deinstitutionalise, socialise and modernise market relations. Régis Debray’s ten year anniversary reading of 1968 (1979: 45-65) advances just such an hypothesis: empowerment as having occurred at the behest of global capital, with 1968 as a kind of spasm internal to the bourgeois sphere and as necessary for a radical reorganisation of industry at the point of the dawning of new modes of production.

The long 1960s is a period which sits unhappily in Zappa's career: the trajectory from arch-satirist and avatar of the underground to Mother-less, berater of consumers - from Freak Out! (1966) to Sheik Yerbouti (1979). To track Zappa's concerns in these matters of social change is to find that the sociological meshes with the scatological. Sexual activity became, for Zappa, the continuum of, and echochamber for, post-1968 freedoms. Initially, such freedoms were enabled by free love and the availability of contraception and abortion, and a leisure sector further given over to facilitating sexual encounters rather than orientated to marriage, mortgage and monogamy. The achievements of communal living (multiple, simultaneous partners: the eradication of the call on or sole loyalty between one and the other), which itself would naturally arise from a culture that had called into existence the Woodstock 
event, ${ }^{2}$ were parlayed into non-phallocentric / patriarchal / hetero-normative practices (dyke communes, cruising and early disco cultures, and Second Wave feminist separatism) and to BDSM cultural ghettos. Although much of this continuum revolved around - especially in Zappa's reading - a simple matter of fucking, in this simple matter of fucking came the re-imagination of a Great Society, as comparable to Lyndon B. Johnson's. Marcuse, writing in 1969, could identify the coming sensibility of a '.. negation of the entire Establishment, its morality, culture; affirmation of the right to build a society in which the abolition of poverty and toil terminates in a universe where the sensuous, the playful, the calm, and the beautiful become forms of existence...' (1973: 33). This is the attempted or assumed development of the long 1960s, from the counterculture and through the liberated cultures of the 1970s. But in the matter of fucking, or as reduced to the matter of fucking, the revolutionary impetus is also curtailed: sexual freedom is not anti-imperialism, libertarianism is not intrinsically pacifist, brotherly love is not necessarily socialist.

The battle for the maintenance of such freedoms after 1968 was not so much to be won in the urban centres - traditionally in advance when it comes to shunning morals and mores, and traditionally the point of origin of new forms of artistic expression, and their more liberated subjectivities - but in the suburbs. The outward spread of freedoms, decentred and diluted, corralled and atomised, in the guise of widened consumer and lifestyle choices, resonated deepest in the fertile grounds of

\footnotetext{
${ }^{2}$ For the integration, or partial integration, of communal living and open relationships into bourgeois society, see Roberts' field reports of commune life (1971). For a perspective from the other end of the decade, concerning post-Stonewall queer subcultures that emerged along similarly open lines, see Edmund White's States of Desire: Travels in Gay America ([1980] 1986). For a discussion on communes and the counterculture see Miller (2002: 327-353).
} 
the suburbs. ${ }^{3}$ It is in this naturally conservative milieu - safely away from the new polarities of city existence in its asset-stripping phase of de-industrialisation - that change can be fully accepted and entrenched. The suburbs become the very vector for the 'normalisation' of alternatives and their embedding, and the location where time is available - away from the bustle and distractions of the city centre, and towards the stretches of commuter tedium so much in need of enlivening. Such an assumption lives on in the urban myth, and pornographic genre tropes, that equate wife-swapping with wealthy but dull suburban areas. Suburban culture requires enticements - the dividends of emancipation - to finesse the influx of the upwardly mobile from the city centres. So the suburbs become the loci of the very institutionalisation of the freedoms of the late 1960s.

If the suburbs, suburban life and suburban cultures, became Zappa's primary concern during the years of Reagan's ascent, culminating at the point of Reagan's coming to office, it is firstly because in Zappa's conceptualisation of the suburbs is the hauntology of the dreams of 1968 in North America, and of freaking out, difference, opposition, outsiderism and dissonance. Secondly, it is because the West Coast suburbs, almost uniquely, represent future shock. Southern California, Zappa's locale, increasingly also became his area of scrutiny, and its people his subject matter. Los Angeles, the largest Californian city, has traditionally functioned as a vision of the near or coming technocratic future for the West, in terms of architecture, technology, and new paradigms of labour and leisure - with Hollywood cast as a propaganda machine in this respect. Hardt and Negri propose the region, and nearby

\footnotetext{
${ }^{3}$ Historians of suburbia find a strong correlation between isolation and the erosion of communities, and new housing sprawl - particularly at this time. See, for example, Putnam (2000: 204 and ff). For Jackson, the balance that comes to favour the suburban over the metropolitan is apparent in the phenomena of the 'center-less city' as evolved in, or by, California, see (Jackson 1985: 265 and ff).
} 
Silicon Valley, as the most advanced sector of the seeming appearance of an imperial 'new Rome': after 'Washington (the bomb), New York (money) [comes] Los Angeles (ether)', where ether is 'communicative' - the immaterial essence of the virtual, (2001: 347, 360).

\section{London and Los Angeles}

The suburbs of the West: metroland, commuterville, the dormitory village, bedroom suburbs, edgelands, the 'edge city', 'the Valley', the stockbroker belt, the hinterland, going 'upstate', 'retiring to' - an area of a negative definition whose denizens, suburbanites, are parochial and home-making rather than, as with the citydweller, masters of their own location. Such geographic and social marginalisation, and a recalcitrant feminisation of a society increasingly associated with suburban home- and family-making (both the female hand in the making of the home, and the permanent re-location of the female to the home, as a housewife and mother, away from the city-centric professions and opportunities) are not typically considered to be matters for celebration, or naturally lending themselves to the concerns of popular culture. The contributors to Visions of Suburbia (Silverstone 1997) tend to eek out the sensibilities of a suburban culture in the changes in kitchen designs, lowbrow television comedies, gardening trends, and run-of-the-mill advertising, and even then find the articulation of a deep ambiguity as to their suburban settings and locales.

A useful exception to this trend is found in Morrissey's work in the mid/late 1990s - that is, in journalistic opinion, at the point of his floundering at what was perceived to be a low-point in a formerly distinguished career. Morrissey’s London suburbs are conceptualised in a way that is diametrically opposed to Zappa's LA suburbs although, crucially, both engage in a sexualisation of suburban existence. The difference is apparent in the way in which Morrissey's suburban music is elegiac, 
finding in the suburbs the ruins of the near-past, while Zappa's conception is prophetic, seeing in the suburbs a vision of the near future.

The sexualisation of suburban existence, for Morrissey, becomes an organising principle for both his imagination of suburbia and his entrée to suburban subjectivities. In suburban sex is the entropy of former aspirations for out, and this explains the persistence of drab, shabby suburban life, and the puzzling immobilisation of those characters encountered who seem too big and restless for these modest corners of the world. The promise of adventure is mapped onto, and crystallised in, the shadowy nature of suburban sexuality. And that adventure is invariably illicit: taboo-busting, class barrier-breaching, or just straightforwardly illegal. In the forgotten hinterlands of suburbia - the abandoned futures of yesteryear - social and civic certainties have weakened to the point that diversion and experience and movement are vertical (upward and downward mobilities, and sexual conquests) rather than horizontal (sticking to your own class and wage bracket: an organising principle in the planning and political economies of suburban sprawls). For Southpaw Grammar (1995) and Maladjusted (1997) Morrissey left his native Manchester for the London suburbs - specifically those parts of Essex, such as Ilford, that remain part of the Greater London conurbation. Morrissey also shifted his focus of observation, from outsider to chronicler, or assumer, of the perspective of a cast of familiar suburban stereotypes rather than outsiders: a variety of proletarian wide-boys, blissfully unaware of their marginality, all of whom Morrissey seems to sexualise.

For 'Maladjusted', where Morrissey's declamatory singing veers from spiteful to pitying as he adopts the perspective of 'semi-perilous lives', the suburbs are formally named. The line of flight is 'around / SW6' and 'the Fulham Road lights' (an agreeable enclave of South West London) and 'a Stevenage overspill' (a London 
commuter town). Our underage callboy, peering at the 'lights in the windows / of all safe and stable homes', may tarry in to those homes and that suburban realm, but only ever temporarily. The song plays with an 'us and them' perspective, dividing those fascinated with the suburbs, but whose critical distance means they can never be truly suburbanite, from those who dwell in these dreary suburbs and get by as best they can (via, in this case, the use of callboys against the deadening hand of suburban and/or family existence). There is a sense that even the 'maladjusted' (both client and callboy) will find a function, and welcome, of sorts, and each other, in suburbia. What liberations occur do so privately and under a cloak of anonymity. Yet such goings-on represent an underground, or psychogeography, of sexual difference, intermingled with the white, working class cultures that remained (despite, and even in the teeth of, Conservative rule), precarious and dangerous. These suburban stretches are a refuge or haven: the place where forgetting can occur. Signs of life, for Morrissey, signal an acquiescence to and accommodation of daily defeat.

Zappa's suburban sexuality is not furtive or discrete, and not class-ridden, since - only a decade after the radical sexual agendas of the Summer of Love - sex itself has been edged into commercial domains. What is underground for Morrissey has become overbearingly omnipresent for Zappa, and the results are a matter for ridicule. Sex has been feminised for Zappa - in the senses of becoming the preoccupation or pastime of the sexually aggressive female, "pace" feminism, and of the 'femininity' of the character of the passive male homosexual, receiver rather than giver, who now looms large. Rounding on sexuality in this way, with sex as the optic through which suburban cultures are presented, examined and decried, inevitably opened up common ground between Zappa and reactionary, moralistic elements then 
ascendant in the public and political spheres. ${ }^{4}$ Zappa's concern is not so much diagnosing mass sexual dysfunctionality (in the manner of Wilhelm Reich's writing of the 1930s) as spinning a Chaucerian picaresque, drawing on specific case studies of sexual bad practice.

Zappa's encounter with the suburbs is less passive than Morrissey's, and not at all celebratory. Zappa's suburbs remain cast as the locale of Pyrrhic victories rather than a defeat: the freedoms of 1968, as filtered through this strata, coloured by it, and giving rise to modes of life that would have been perceived, at the time of We're Only In It For the Money (1968), as the minority preserve of pop stars, hippies and freaks. So Zappa, whose relationship with 1968 was never as straight-forward as the iconic use of his image at that time would have suggested, came to strike an ambiguous, even contradictory relationship with suburban cultures. They become a constant theme in Zappa's music from the mid-1970s onwards - gaining momentum especially (and overtaking concerns more centred on the mythology of the rock band on the road) at the point of the soundtrack to the suburbs engulfing the pop charts: the second wave of commercial (rather than underground and gay nightclub-orientated) $\operatorname{disco.}^{5}$

\footnotetext{
${ }^{4}$ The argument could be made - although it is beyond the scope of this article - that Zappa's attempt to block any such commonality and disavow such company resulted in the self-consciously outrageous strain in his work.

${ }^{5}$ For disco as the underground soundtrack to queer subcultures and the burgeoning New York gay nightclub scene, see White ([1980] 1986: 269-285). For the commercialisation of disco and the anti-disco backlash, see Shapiro (2005: 194, 226) who dates this phase as 1977-1979. The release of Sheik Yerbouti in 1979 (the title a play on the disco classic '(Shake Shake Shake) Your Booty' by KC and the Sunshine Band), which contains the attack on the exclusivity of disco culture, 'Dancin' Fool', falls into this anti-disco timeline too. Zappa, in his autobiography, posits disco as only ever a sly disguise of 'corpo-rock', enabling bar owners to replace live music with recorded music and, for those who 'sort of "looked good", to take drugs and engage in casual sex, (Zappa, Occhiogrosso
} 
The 1976 album Zoot Allures concludes with the track 'Disco Boy', as if in response to Zappa's update of Dylan's 'Twenty years of schooling / And they put you on the dayshift' (of 'Subterranean Homesick Blues'): an update articulated in the opening track, 'Wind Up Workin' in a Gas Station'. The inexorable 9-5 fate of the protagonist is clear: 'your education won't help you... / you're gonna wind up working in a gas station'. As with the protagonist of Saturday Night Fever (dir. John Badham, 1977), the worker's compensation comes in escapist weekends away from suburbia and in city centre discos. 'Disco Boy' is typical of a foundational concern of Zappa's, the commercialisation of countercultures, but beyond this, however, little coherent is said. The disco boy is derided for his effeminacy (referred to as 'honey') and yet his care over his appearance, the narrator seems to begrudgingly concede, leads to the promise of success with a woman he meets on the dance floor - albeit one who then elopes with the disco boy's friend. The very Zappaesque punchline is that the disco boy's dance floor dexterity is now needed for compensatory, masturbatory ends, once he has returned home alone. Auto repairs or autoeroticism - the choice seems ultimately only in respect of what the character is asked to do with his hands: be they gas-stained ('Let me see your thumb' is a refrain in 'Wind Up') or semenstrained ('thank the Lord that you still got hands / to help you do the jerking that'1l / blot out your disco sorrow').

Other than an incorporation of disco-like, Bee Gees-esque alto voices in harmony, 'Disco Boy' evidences little comprehension of the sonic palette or even beat of disco. Rather, the song contains wildly off-the-mark synthesiser sci-fi rumbles, reminiscent of the threatening tympani bent notes of 'Who Are the Brain Police?'

1989: 202). In his film Baby Snakes (dir. Zappa, 1979), Zappa also speaks approvingly of the 'Disco Sucks' tshirts he spies in the audience in the 1977 concert footage. 
from Freak Out!, and which, in terms of a semiotics of sound, can be taken to connotate disco as the then-coming sound: low supercomputer growls, as found in 1970s sci-fi dystopia/disaster films. This future world of disco only offers a prospect as sexually frustrating and spiritually bankrupting as same old past. It is as if, within the space of a few years, the very inverse of the project of the communes beckoned: isolation over collectivism and hardened character armour (to use Reich's term) over the de-alienating experiences of nudity and nature. Even the qualified but radical potential of 'the freak', for Zappa, would have seemed to have been sublimated into this post-1968 culture of conformity, as represented by disco: in 1978, Chic's 'Le Freak' would be a disco anthem, with the instruction or social advice to 'freak out!' for this 'new dance craze', as happening in Studio 54, and with equation in the chorus of 'Le freak - c'est chic'. This cultural homogenisation, as exerting a centrifugal force on the suburban cultures, and which is established in a dialectical manner on Zoot Allures (gas station to discotheque), becomes Zappa's chief concern at the point of the ascendency of neoliberalism. ${ }^{6}$

\section{Zappology and Reaganomics}

Zappa's live popularity in the US began to wane in the late 1970s. Zappa claimed his initial fans had simply grown out of the more youthful pastime of the live concert ('... now that they have wives, kids, mortgages, day jobs...'; quoted in Miles (2004: 277)) and so geared his music to a younger audience, while Miles reasons that

\footnotetext{
${ }^{6}$ This neoliberal phase, discussed here in relation to Reagan, can be said to have been merely embodied in the figure of Reagan (a nightmare figure particularly for Californians of the 1960s), and identified with Reaganism. Neoliberalism itself is typified in post-Marxist critical thought as the time that had come, after the close of the long 1960s for, in the US context, monetarists, the New Right, exponents of the Chicago School and Cold War Warriors now unencumbered by Nixon, etc. Bifo, for example, refers to 1977, as 'the year of the end of the twentieth century: the turning point of modernity', (Berardi 2009: 15).
} 
the shift occurs in respect to Zappa's falling out of touch with the younger audience, resulting in his touring more extensively outside the US, (2004: 281). But looking to age disparities risks the danger of overlooking a socio-political change, and one that increasingly marginalised anti-establishment sensibilities.

The film Baby Snakes records Zappa's band and entourage of the Sheik Yerbouti period: the bunker mentality that Gray would rail against is apparent in the film's claustrophobia: ${ }^{7}$ small studios, cramped backstage areas, airless audition rooms, the relatively tight space in which the band performs live, and with the indistinct audience area mostly a haze of bluish light. The effect, across the film's two and three quarter hours running time, is stifling. But in its final minutes - in a sequence positioned after the closing credits - Zappa is seen emerging from the concert venue, is walked through a scrum of fans, and whisked off in his car. It is a startlingly sudden ethnographic lurch into the world outside. Sartorially, the fans themselves can be identified precisely: children of ' 68 , still living the counterculture, albeit confined to evenings and weekends, since their smart-casual clothes and hair (and uniform whiteness) speak of a creeping accommodation of professional life now that they are in their thirties. The glasses, and the air of the educated comfortably slumming it, ${ }^{8}$ suggests positions in the ascendant information technology industries, university research, and tertiary sector management. These are not the deracinated wasters of the mid-West who crowd the frame for Sex Pistols gigs in D.O.A. (dir.

\footnotetext{
${ }^{7}$ As well as being an unapologetically patriarchal, authoritarian bully, and essentially friendless and cold, Zappa is, for Gray, ' ... a man who spent most of his life locked away in a basement, inside a semi-fortified house...', (1994: 238). This extraordinary outburst in the final pages of a relatively placid biography seeks to effectively undermine the high moral ground from which Zappa, for Gray, evidently found himself free to damn the wretches he encounters; see (Gray 1994: 236-239).

${ }^{8}$ In the absence of any demographic data, the assumption that Zappa's sexual crudity played and appealed to blue collar workers, found in much critical writing on Zappa, seems like straight class prejudice.
} 
Lech Kowalski, 1980) or the appealing, healthy masses who pack the discotheques of Thank God It's Friday (dir. Robert Klane, 1978). ${ }^{9}$ Rather, they are those whose imminent move to suburbia would mark the point at which they made their peace with the world - a truce dramatised in the suburban lifestyles and creative professions as awaiting this generation in the television series thirtysomething (ABC, 1987-1991). This motley collection of weekend freaks, waiting to high five Zappa, were perhaps his last real live audience. And their innate, generational preference for difference would be so thoroughly marginalised by Reagan's coming to office that only one option would present itself at this crucial juncture: to settle down, come into their inheritance, and so renounce earlier ways. Such youth excesses would be demoted to nostalgia and fetishism: for one protagonist of thirtysomething, an advertising executive, in his treasured collection of Haight-Ashbury posters.

Despite Zappa's then focus on the suburban locale of this coming entrenchment, and the counterattack found in his work, his own marginalisation can be accounted for by this sea change too. The dissipation of emancipatory impulses of the 1960s, and the lack of empathy for dissident cultural projects of the 1970s (which would account for Zappa's animosity to disco, wariness of punk, and lack of engagement with rap and hip-hop), would leave his oppositional politics high and dry and his confrontational, antagonistic tendencies with an ever-diminishing audience. Zappa would retreat, as Gray notes, to his basement.

Sheik Yerbouti, which is a last hurrah in terms of this timeline, was released in March 1979. The ten subsequent sides of vinyl that constitute Zappa's journey

\footnotetext{
${ }^{9}$ And indeed Zappa here is a celebrity, kept apart from the crowds, rather than the ring master or MC figure of the burgeoning countercultural scene of his appearance in Mondo Hollywood (dir. Robert Carl Cohen, 1967), or for Head (dir. Bob Rafelson, 1968) in which he comments upon the scene in passing, rather than being seen as an Alist survivor, or product, or even purveyor of products, of that scene.
} 
through the suburbs coincide with Reagan's successful presidential campaign and ascent to office, in January 1981: the Joe's Garage albums were released SeptemberNovember 1979 and You Are What You Is in September 1981. In these predominantly studio albums, the coming America - Reaganite, embourgeoisified, materialist, Puritanical (and its flipside: discourses of identity politics, feminism and gay rights in particular, as engendering new underground cultures of sexual emancipation) - is examined almost entirely in sexual terms.

\section{Suburban Accommodations}

Sheik Yerbouti initially dwells on the detritus of suburban existence, via a number of concerns, only to transcend them in its final 'movement'. The first of the album's four sides begins with a track that would reduce the romanticism and intimacy of Peter Frampton's popular hit 'I'm in You' (and 'sully' the innocence of doo-wop, which the song fondly parodies) to the simple boast and promise of repeated intercourse, made via mock-sleazy intonation, and with the proviso that the unpleasant experience of previous intercourse will not waylay or delay the coming intercourse ('I Have Been in You'). 'Flakes' has been taken as an attack on the sloth and criminal nature of union-protected blue collar works in a way that shares a sensibility with the pro-Reagan press of the late 1970s, ${ }^{10}$ and includes a parody-cameo by the former poet of the 1960s proletariat: Bob Dylan. 'Broken Hearts are for Assholes' seems to chart an odyssey through underground gay clubs, with the 'lonely guy' protagonist reduced to a literal 'asshole' for a series of anonymous sexual encounters. However, such sexual practices then seem to be imported back into heterosexual relations, with a female now promised anal sex and fisting. In the later track 'Bobby Brown (Goes Down)', which also parodies doo-wop, feminist

\footnotetext{
${ }^{10}$ A point of debate between Lowe (2006: 140 and ff) and Watson (1993).
} 
aggression and the confusion arising from gender-bending sends an all-American-boy on a similar gay odyssey of S\&M and wet sex. ${ }^{11}$ The flatness of the lyrical imagination (the one humorous lyric lamely attempts to rhyme 'afternoon' and 'tampon' by inserting an extra 'o' into the latter, although the spoken words of 'Assholes' record authentic gay slang of this period) are in profound contrast the lyricism of the guitar playing, which is constantly surprising and inventive. The general rockist tone, and concert hall echo of the liveness of some of the recordings introduced into the studio material, lends an audio depth to the album.

This depth is found via Zappa's palimpsest 'xenochronic' techniques, ${ }^{12}$ as utilised on Sheik Yerbouti, and its final movement is marked by a melancholic xenochronic timbre, as applied to a lament for the collective passions that used to drive free love ('Wild Love'), ${ }^{13}$ and the fate of disorientated hippies. The album ends describing a retreat back to the familial home for such idiosyncratic, Syd Barrett-like characters ('You ain't really made for bein' out in the street / Ain't much hope for a fool like you / 'Cause if you play the game, you will get beat'), followed by a 'retreat', for Zappa, into extended, melancholic soloing ('Yo Mama'). In this soloing, in the rockism and the space of the production, and this concern with the diminishing

\footnotetext{
${ }^{11}$ Medhurst notes the particularity of homosexuality as a threat to the perceived calm of suburban life: the difference within the vistas of sameness and the ending of the conventional nuclear family unit - for whom the suburbs exist, (1997: 266). In this respect, Zappa's conceptualisation of the suburbs (and this analysis posits all these albums under discussion as 'concept albums') reproduces the stereotypical fears of what excessive things might be going on 'out there' - that is, in the environments of the everyman.

${ }^{12}$ The technique of splicing of elements of live recordings into or (in absolute atemporal or polyrhythmic counterpoint) onto studio recordings. Xenochrony, in dissolving the studio/live dichotomy results in music that can be seen as a total narrative (spontaneous/planned, contemporary/archived, found/recreated) of musical creation.

${ }^{13}$ Such collectivity is particularly apparent in the 1978 quadraphonic mix of 'Wild Love' with its multiple voices separated out into a call-and-response oratorio, released in 2004 on the album QuAUDIOPHILIAC.
} 
legacies of 1968, which is also a concern with time passing and youth giving way to middle age, Sheik Yerbouti seems to mark the end of an era. Triple-album Joe's Garage strikes, in its penultimate track, an equally transcendent note: the extended soloing of 'Watermelon in Easter Hay', which marks the retreat of the protagonist (imprisoned, his pop star days well and truly over) into a world of fantasy: the track is introduced as the dream of an 'imaginary guitar solo'. In place of these fading embers of the counterculture seems to come its very antithesis: the San Fernando Valley over Laurel Canyon, and the commerce surrounding 'love', as commodity, over communal and free love.

Joe's journey begins in the suburbs and with a small town mentality: the album tracks band rehearsals in a parent's garage to the excesses of aspirant rock star life, and a series of flaky life-style concerns, including Scientology, against the backdrop of a creeping Big Brother state that seems as much totalitarian-left as dictatorial-right. ${ }^{14}$ The path to stardom (soon curtailed by sexually transmitted disease, organised religion, and gaol) is the exit from suburbia for Joe, and Zappa is precise about the locations and parochial locale in the stage directions: 'a boring old garage in a residential area' ('Joe's Garage'), '[a] festive CYO [Catholic Youth Organization] party with crepe paper streamers' ('Catholic Girls'), '[b]ackstage at the local Armory' ('Crew Slut') and The Brasserie nightclub in Miami for 'The Wet TShirt Contest'. This track, in particular, paints a depressingly mundane vision of suburban sexuality - of a type that would later be milked for pseudo-amateur softcore pornography (particularly the Girls Gone Wild series), and would lend Hollywood-

\footnotetext{
${ }^{14}$ In the 'stage directions' supplied with the album lyrics, Zappa's vision of the future - which, he states, was inspired by the Iranian Revolution - is one in which everyone collects welfare payments and spends the money on the repair of broken consumer goods (in this respect, the song shares a concern with 'Flakes').
} 
filmed pornography a characteristic mise-en-scène (the fitted kitchens and airy living rooms of rented condominiums).

Mary, having abandoned Joe for a life of groupie-dom, is now down on her luck and so enters the wet t-shirt contest for the prize money she needs for the bus fare home. The MC, defrocked priest Buddy Jones, urges on 'the charming Mary from Canoga Park' (in the San Fernando Valley) and leers at both her and the audience (referred to as 'mongoloids squatting on the dance floor' in the stage directions). Jones is voiced by Zappa, and the track is not so different from the straight live recording 'Panty Rap', from 1981's Tinsel Town Rebellion, during which Zappa actually instigates a tamer version of such an event - inviting female audience members to throw underwear onto the stage for his inspection, something typical of his live shows at this point.

In Mary's performance comes an expression of the ambiguity of Zappa's take on suburban sexuality - both deriding the cultures of the commercialisation of sexuality, and yet seemingly finding in its practitioners an undeniable spark of humanity. Mary seems to remain blissfully unaware and colludes happily in her sexual exploitation, both here and at the hands of Catholic boys, Father Riley (the former Buddy Jones), the band members and crew of another touring rock group, and seemingly her biological father. As voiced by Dale Bozzio, Mary comes across as feisty and ready to party: an attractiveness that arises from an innocence and naivety that remains intact despite her dire history and situation. The exploitation does not impinge on a personality built on a willingness to please, and a lack of awareness of any other option. Even her lack of education ('Where ya from?', 'The bus!'; the giggling and squealing; 'Here I am!'; 'I'm dancing!') is winning. And, indeed, Mary 
triumphs in the competition: a validation of such an engaging persona in the commercial cultures of sexuality.

Certainly these characteristics represents a type and trope typical of pornographic models, and a female persona commonly dissected by feminists (the virgin/slut dichotomy), but in the context of encroaching and dehumanising state control, Mary stands out as - in Shavian terminology - an authentic life-force. The universal of music, theorised by Zappa as the foundational, youthful domain of authentic human expression (be it dancing, doo-wopping, guitar-playing, and so deserving of a rare dose of sentimentality, in the album's opening track) and thus to be censored, is embodied in the figure of Mary. And, reappearing in a vision later in the narrative (for 'Packard Goose'), she is given the somewhat Ruskin-esque moral of the story to delivery: that music is absolute and transcends the relative values of information, knowledge, wisdom, truth, beauty and love.

The track that 'The Wet T-Shirt Contest' most closely resembles is another blast of mindless chatter: 'Valley Girl' (voiced by Moon Unit Zappa, on the 1982 album Ship Arriving Too Late to Save a Drowning Witch). And this time, despite the exaggerated nature of this pastiche of valley-speak, whatever its sociological pretentions, the traction was such that the song became a radio hit and, establishing an urban type and spawned a minor 'Valley Girl' industry in the early 1980s (which eventually included two feature films). ${ }^{15}$ In that the focus of modernity in these two tracks is the valley girl, the question is not over the problematic of the commercial cultures of female liberation - a concern of Third Wave feminism which floundered on the matter of sexual self-performance, as in a wet $\mathrm{t}$-shirt competition (with this

\footnotetext{
${ }^{15}$ Despite his strong distaste for the culture of the San Fernando Valley (see, for example, Miles 2004: 305, and Watson 1993: 397), Zappa's career received a considerable boost from its unwitting promotion.
} 
'raunch culture' identified by Levy (2006) as now virtually institutionalised). Nor is it a question of whether valley culture oppresses and retards (in the manner of survival of the stupidest) womankind, and degrades participants and observers. Rather, Zappa's presupposition - intentional or otherwise - seems to be that both these tendencies are in operation simultaneously. For this reason, the track - and much of the First Act of Joe's Garage - is caught between celebrating and condemning simultaneously. This ambiguity structures 'The Wet T-Shirt Contest', 'Valley Girl' and even (as the male subjectivity as conversant with such women), 'Titties \& Beer' (from 1978's Zappa in New York) since all three contain dialogues between two voices and positions (Buddy Jones and Mary, Moon Unit and nondescript male singing voices, the unnamed protagonist and the Devil).

The future shock culture of these suburbs, as rendered and explored in sexual terms, explains why disco and valley girl cultures should be received by Zappa in such a negative way rather than just acknowledged or dismissed as passing trends. The imminent and place-specific nature of the promised freak explosion of Freak Out! presupposes an authentic culture that was anything but homogenising and massproduced was about to break surface. Now, where there were once hungry freaks, Zappa finds valley girls, and where there were once hungry esteemed musicians of the Magic and Mothers of Invention bands, Zappa finds soulless computer muzak. And love in the suburbs, in Lowe's analysis of Zappa especially, is the motor of this homogenisation, this pervasive blandness, now occurring in terms of romance and related feelings (sexual, sentimental, communicative) reduced to commodities and clichés, especially by record companies.

Zappa's cynicism in this regard is one that seeks to look beyond the façade, not so much to find the myths threadbare, but to find an unstable state of continual 
rupture in homogenising processes. Here Zappa's position becomes unclear. Sociological pretentions aside, where does he actually stand? For or against Mary and the Valley Girls? If there is no straight answer is it because there is a paradoxical and catholic irrationalism at work in Zappa's love for, and time spent with, the very figures he pities? The net result is the contemporary and typically postmodern actuality: irresolution as a state of constant weirdness, as amplified in the suburban margins. It is this position that is closest in Zappa to a critique of political economy, and can be placed in a more general strain in popular American culture, incorporating Matt Groening (whose often cites Zappa's work as influential), the 1980s films of John Waters, Tim Burton and David Lynch, the re-imagination of suburban spaces enacted in the resurgence of skateboarding culture, and the room and buildingsplitting of artist Gordon Matta-Clark.

\section{... What You Is}

Only the constant manifestations of the biological nature of sexuality, its very materialism, and the extended and often dissonant guitar soloing in Zappa's music, seem to cut through this confusion. When love is reduced to mere bodily fluids and parts, and the cast silenced for Zappa's frequently hard-edged guitar-playing (where the plectrum is used in an aggressive manner on the strings, and the phrasing resolutely avoids repetition and familiarity, or even locking into a groove or given time-signature), the prurient framings, and uneasy preoccupations of his narratives, can be momentarily neutralised. Biological essentialism, and an essentialism or primacy of music and musicianship, are easier, and less disorientated, philosophical positions, and so plug the social and ideological lacuna that bewildered Zappa. And such essentialism is translated even into the tautology of the title of You Are What You $I s$. 
Unlike Sheik Yerbouti, You Are What You Is offers very little musical respite. Drenching notes the 'stifling flatness' of the 'evenly-mixed palette' of the album (2005: 93, 98 footnote 10). The majority of the album is taken up with near-constant vocals, moving relentlessly, and with jarring speed (and often via segue rather than formal endings and beginnings as lyrics leak from one song to the next) across a succession of suburban targets. The attacks are unsparing and the sexual subject matter unremittingly joyless: idealist teenage rebellion enmeshing with stimulant abuse ('Teen-age Wind'), infidelity and relationship termination, with the object of lust seemingly acknowledging the male's abusiveness ('Harder than Your Husband'), sexual frustration and pleading for intercourse ('Doreen'), 'cosplay' and/or fetishism and oral sex ('Goblin Girl'), and all within less that the first quarter of an hour. Thereafter the album returns to oral sex and female stupidity as the defining characteristic of a deceased character ('Charlie's Enormous Mouth'), a bungled suicide attempt by a character craving attention ('Suicide Chump') and the threat of violence to a groupie described as ugly, made once the narrator has tired of receiving oral sex from her ('Jumbo Go Away’). ${ }^{16}$ Lyrics are often functional, repetitive during outros, and scan comfortably within their time signatures. And these character / event sketches, even if improvised by Zappa at speed or considered a priori to be secondary

\footnotetext{
${ }^{16}$ This last track seems to be the breaking point for Zappa apologists. Lowe, who feels obliged to perform interpretative acrobatics of the most impressive kind throughout his study, is finally defeated by 'Jumbo Go Away', (2006: 175-176). Likewise Watson, who breezily promises a robust defence of his subject at the outset of his study, comes to level criticism at the song - even directly, albeit tentatively, to a dying Zappa, (1993: xxx and 548-9).
} 
to the music, or as the vehicle for singing in character, or enabling riffing off a wideranging selection of musical genres, only reinforce a sense of pinched horizons. ${ }^{17}$

This wallowing in the enemy camp on the part of Zappa again presupposes a double determinant: both celebrating and condemning. And yet, in the sheer gusto and indestructibility of Zappa's array of emblematic types, the personae dramatis of the drama of this concept album, there is a vitality that is uncontained by conformity. Watson's claim for You Are What You Is, that the album 'remains one of the most ambitious public stands against Reaganism in the 80s' (1993: 395) - sketchy in Watson's appraisal - can be acknowledged in this context. Along with the absence of sonic depth is an absence of the hauntology of the dreams (if not the nightmares) of 1968. The contemporary sheen of the album, its speed and flash, its peppy, bubblegum pop, and even its debt to punk (in its longueurs and repetitions) makes for the music of the new society that the album addresses.

In the album's concluding minutes, the dividend of Zappa's conservatism is apparent. Despite the preceding trawl through the detritus of modern society, an intrinsic, human, anti-Reagan sentiment emerges. 'I Don't Want to Get Drafted' speaks of a defiance (these individuals simply do not want to risk life and limb), as a totality (the lyrics are taken up by chorus of innumerable voices), underscored by a fear as to where the Reagan years will lead. This sentiment is from one who knows. Zappa recalled the psychic disturbance of militaristic violence of the late 1960s,

\footnotetext{
${ }^{17}$ At any rate, the precision and deftness of the lyrics of 'Heavenly Bank Account', concerning another Zappa bugbear, the televangelist (where the comically complex time signatures mimic the mystifications and confusions confronted by the IRS on inspecting this citizen's tax returns), and the fragmented existential flailings of 'You Are What You Is', concerning extremes of personality reinvention (in the MTV-banned promotional video applied to Reagan), which could be termed Beckettian, suggest that the lyrics were not necessarily prepared without due care.
} 
winding haphazardly and poisonously back into the counterculture, and his own midwifery of the resultant live 'happening':

I handed them [three Marines in uniform] a big baby doll and said, 'Suppose you just pretend that this is a "gook baby".' They proceeded to rip and mutilate the doll while we played. It was truly horrible. After it was over, I thanked them and, with a quiet musical accompaniment, showed the ruined parts of the doll to the audience. Nobody was laughing. (Zappa, Occhiogrosso 1989: 94; Zappa’s italics)

The impression is given that the milieu upon which Zappa poured his scorn, the new suburbs of the ascendant 'plastic people', was not exactly unpleasant. Zappa is able to articulate, if not find a synthesis between, the enviable freedoms given to the common man while, at the same time, he attacks their misuses. ${ }^{18}$ In the frescos of merrily fellating groupies and predatory disco dancers there is no sense of anything other than a collective, endemic stupidity - and one finessed by the trimmings of material wellbeing and sexual opportunities. Yet such world view, prompting this misanthropy, can remain the foundation of celebration when the future anterior to these suburbs is suddenly so threatening: the return of the Old West, with all its militaristic hubris, chauvinistic righteousness, and imperial violence. For an aside in 'The Blue Light', Zappa appropriates and subverts the title of Reagan's old cowboy show for a resounding warning: 'Death Valley Days - straight ahead!'

\footnotetext{
${ }^{18}$ The populist forms of You Are What You Is raise a supplementary question: to whom is this satire usefully being addressed? One answer, albeit presumably beyond the intentions of Zappa, was East Bloc dissident music listeners. The album's position matches elements of a pre-1989 anti-Communism perspective: the notion of the excesses of consumer society as understood to represent a goal to be achieved nonetheless since excesses could then be moderated. In this respect, Zappa can be read in the cultural front of the war against the Soviet Union, also claimed (and claimed as successful, even if retrospectively) by the Reagan administration.
} 


\section{Bibliography:}

Berardi, F. 2009. Precarious rhapsody: Semiocapitalism and the pathologies of the post-alpha generation. London: Minor Compositions.

Clover, J. 2009. 1989: bob dylan didn't have this to sing about. Berkeley, Los Angeles, London: University of California Press.

Debray, R. 1979. A modest contribution to the rites and ceremonies of the tenth anniversary. New Left Review, I/115 (May-June), 45-65.

Drenching, T. H. F. 2005. 'Watermelon in Easter Hay": The function of the reverb unit \& the poverty of the individual spirit" in Academy Zappa: Proceedings of the First International Conference of Esemplastic Zappology (ICE-Z), edited by B. Watson and E. Leslie. London: SAF Publishing, 89-98.

Gray, M. 1994. Mother: The Frank Zappa story. London: Plexus.

Hardt, M. and Negri, A. 2001. Empire. London: Harvard University Press.

Jackson, K. T. 1985. Crabgrass frontier: The suburbanization of the United States. New York: Oxford University Press.

Levy, A. 2006. Female chauvinist pigs: Women and the rise of raunch culture. London: Pocket Books, Simon \& Schuster.

Lowe, K. F. 2006. The words and music of Frank Zappa. Westport, Connecticut, London: Praeger.

Shapiro, P 2005. Turn the beat around: The secret history of disco. London: Faber and Faber.

Marcuse, H. 1973. An essay on liberation. Middlesex: Penguin Press. 
Medhurst, A. 1997. Negotiating the gnome zone: Versions of suburbia in British popular culture, in Visions of suburbia, edited by R. Silverstone. London and New York: Routledge, 240-268.

Miles, B. 2004. Frank Zappa, London: Atlantic Books.

Miller, T. 2002. The Sixties-era communes, in Imagine nation: The American counterculture of the 1960s \& 70s, edited by P. Braunstein and M. W. Doyle, London: Routledge, 327-352.

Putnam, R. D. 2000. Bowling alone: The collapse and revival of American community. New York: Simon \& Schuster Paperbacks.

Roberts, R. E. 1971. The new communes: Coming together in America. Englewood Cliffs, New Jersey: Prentice-Hall, Inc.

Watson, B. 1993. Frank Zappa: The negative dialectics of poodle play. London: Quartet Books Ltd.

White, E. [1980] 1986. States of desire: Travels in gay America. Picador, London. Zappa, F. with Occhiogrosso, P. 1989. The real Frank Zappa book. London: Picador. 